\title{
Experience with screening newborns for Duchenne muscular dystrophy in Wales
}

\author{
D M Bradley, E P Parsons, A J Clarke
}

\begin{abstract}
Objectives-To assess the acceptability of screening newborn boys for Duchenne muscular dystrophy. Design-Screening is offered on the basis of informed consent in response to an information sheet entitled "A new test for baby boys-Do you want it?" The programme includes a prospective long term evaluation of family responses to early diagnosis and a comparison of their experiences and perceptions with those families who have undergone the later traditional clinical diagnosis.
\end{abstract}

Setting-All maternity units throughout Wales. Samples obtained through screening programme for phenylketonuria and congenital hypothyroidism.

Subjects-Those families whose son had a positive screening test.

Main outcome measures-Creatine kinase activity. Venous blood test to confirm positive result. Molecular genetic mutation analysis. Muscle biopsy and dystrophin analysis. Qualitative measure of satisfaction among affected families.

Results-34219 Boys have been screened and nine affected families have been identified. Eight families were very positive about the programme. Three chose not to complete the diagnostic process.

Conclusion-The programme should continue to permit a full evaluation of the issues involved and should serve as a model for other initiatives within the community for genetic disease.

\section{Introduction}

Screening of newborns for Duchenne muscular dystrophy by measurement of blood spot creatine kinase activity has been technically possible since a suitable assay was devised in the mid 1970s.' Since then it has been offered on a limited basis in Germany ${ }^{2}$ and as a routine service in Lyons, France, ${ }^{3}$ and Antwerp, Belgium. There have also been pilot programmes in Iowa, USA, ${ }^{1}$ New Zealand, ${ }^{4}$ and Edinburgh. ${ }^{5}$ More recently, after the advances in the molecular genetics of Duchenne muscular dystrophy, programmes have started in Manitoba, Canada, ${ }^{6}$ Pennsylvania, USA, and now in Wales.

Before the advent of molecular genetics, screening of newborns in the United Kingdom was generally regarded as ethically unsound because no treatment was available; it offered little advantage to the family other than the possibility of terminating all subsequent male fetuses, more than half of whom would be normal. Apart from a brief pilot study in Edinburgh ${ }^{5}$ it was not undertaken.

With the isolation of the gene responsible for Duchenne muscular dystrophy ${ }^{7}$ it became possible to track the defective gene in most pedigrees and to offer increasingly accurate prenatal diagnosis either by deletion analysis in many cases or by using linked markers. Consequently, although the condition was still untreatable the neonatal identification could facilitate reproductive choice in further pregnancies in the immediate and the extended family. This led to a reassessment of the ethical issues surrounding newborn screening. The common clinical experience of diagnosing two (or occasionally more) affected boys simultaneously in a single family has to be weighed against the availability of prenatal diagnosis in future pregnancies once the first case has been identified. In addition, diagnostic delay causes considerable distress to families and may result in subsequent bitterness if the child's symptoms are not taken seriously by family or health professionals or if a second affected boy is born. Despite such considerations, there has been concern that a neonatal diagnosis would interfere with the normal social and emotional growth and interaction of child and family.

Gardner-Medwin ${ }^{8}$ proposed screening 18 month old boys who are not walking as an approach to the problem of delayed diagnosis. This should detect half of affected boys. Such a project was tried in Wales ${ }^{9}$ and though it did identify cases, logistical difficulties in community health care made the rate of detection unacceptably low. After this an attitude survey found that most new mothers were in favour of screening newborn boys. ${ }^{10}$ This group stated their (hypothetical) preference for the early diagnosis of serious disorders such as Duchenne muscular dystrophy even when no treatment was available. This led to the present study.

The six programmes currently in place worldwide vary in their structure as they function within the constraints of their particular national health care systems. Here we present data from the programme throughout Wales, which started on 1 July 1990. The aims were to give families reproductive choice in future pregnancies; to enable them to plan for the future with a child with a disability; to avoid the experience of a prolonged diagnosis; and to identify a presymptomatic cohort who may benefit from future treatments. The principle and practice of the programme were assessed to determine whether screening was helpful from the perspectives of both families and health professionals. Screening for Duchenne muscular dystrophy was introduced as a parental option for baby boys in addition to the routine tests for phenylketonuria and congenital hypothyroidism. The decision to offer the test on this optional basis is unique within the context of neonatal screening. This led us to monitor the implementation of the programme closely and to modify follow up protocols in the light of our experience. This programme is also unique in including both prospective developmental and social evaluations, which will be described in detail elsewhere.

\section{Methods}

Informed consent is sought from parents on the basis of an information sheet entitled "A new test for baby 
boys-Do you want it?" printed on blue paper. Midwifery staff are asked to give this to the mother sufficiently ahead of her discharge from hospital so that she can ask midwifery or paediatric staff any questions which might occur to her or her partner. When the community midwife calls at home on day 6 or 7 to take the heel prick blood sample for the usual screening tests she asks whether or not they want their son tested for Duchenne muscular dystrophy and marks the screening card accordingly.

Our protocol (available on request from the authors) for the follow up of a positive test result was governed by three main considerations. Firstly, we are offering a family the diagnosis of a lethal untreatable disorder in an apparently healthy baby; secondly, the protocol was designed so that we could modify practice in the light of experience; and, thirdly, families should have choice at every stage from the initial screening test to a confirmed diagnosis. Clearly this is different from the normal practice in routine neonatal screening. To help with consistency of approach paediatricians in each of the nine health districts in Wales were asked to choose one or more of their number to be nominated for this project.

After a positive test result the family practitioner and health visitor are contacted when the baby is about six weeks old to develop a social profile of the family and decide how best to approach them to offer a venous blood test to confirm or refute the screening test. Before the family are contacted an appointment is arranged with the nominated paediatrician so that they can see the family within a day of their being approached by the primary health care team. At this meeting the paediatrician ensures that the family are aware of the screening programme and the options that are open to them. If they agree a venous blood sample is taken and another appointment arranged within 24 hours to give the result so that the period of uncertainty and anxiety is minimised. After the result of the venous creatine kinase test has been given and explained families are invited to take part in the social evaluation of the screening programme. Should the screening test result be confirmed the family are offered genetic counselling and the opportunity to further the diagnostic process, initially by molecular genetic mutation analysis and subsequently by muscle biopsy and dystrophin analysis.

Creatine kinase activity is measured semiquantita-

TABLE I-Details of screening and test results for Duchenne muscular dystrophy during 1 fuly 1990 to 30 fune 1992

\begin{tabular}{lrr}
\hline \multicolumn{1}{c}{ Variable } & No \\
\hline Samples received & 77728 \\
Samples labelled as male & $38357(49 \cdot 3 \%)$ \\
Samples for which test refused & $2081(5 \cdot 4 \%)$ \\
Samples for which option not stated & $2057(5 \cdot 4 \%)$ \\
Samples for which test requested & $249(89 \cdot 2 \%)$ \\
Creatine kinase increase & $16(1: 2138)$ \\
Confirmed creatine kinase increase & $9(1: 3802)$ \\
Transient creatine kinase increase & $7(1: 4888)$ \\
\hline
\end{tabular}

TABLE II-Summary of findings in families with confirmed positive test results

\begin{tabular}{|c|c|c|c|c|c|}
\hline Family & $\begin{array}{c}\text { Venous } \\
\text { creatine } \\
\text { kinase (IU/1) }\end{array}$ & Exons deleted & $\begin{array}{l}\text { Result of muscle } \\
\text { dystrophin } \\
\text { analysis }\end{array}$ & $\begin{array}{l}\text { Maternal } \\
\text { creatine } \\
\text { kinase } \\
\text { activity }\end{array}$ & Family history \\
\hline 1 & 7070 & $47-52$ & Duchenne & Elevated & Elder sibling ${ }^{\star}$ \\
\hline 2 & 2442 & 19 & Duchenne & Elevated & Elder sibling ${ }^{\star}$ \\
\hline 3 & $>5000$ & $45-50$ & Deferred & Elevated & \\
\hline 4 & 3868 & $46-50$ & Duchenne & Elevated & \\
\hline 5 & 3150 & None deleted & N/A & Elevated & Uncle \\
\hline 6 & 8100 & $48-52$ & Duchenne & Elevated & \\
\hline 7 & 9200 & None deleted & Deferred & Normal & \\
\hline 8 & 5000 & None deleted & Duchenne & Normal & \\
\hline 9 & 8300 & None deleted & Deferred & Elevated & \\
\hline
\end{tabular}

${ }^{\star}$ Diagnosed after positive screening test on younger brother. tively, fluorimetrically by a semiautomated version of that previously described. ${ }^{9}$ Though screening programmes for Duchenne muscular dystrophy have detected cases of Becker muscular dystrophy, ${ }^{311}$ whether all or any cases will be detected in this programme is not known. Until the results of long term follow up are available the ability of our creatine kinase assay to detect Becker cases remains uncertain.

\section{Results and discussion}

The overall figures for the first two years are given in table I. There have been a total of 16 positive test results, nine of which were confirmed on a subsequent venous sample, giving an incidence of 1:3802 male births. The creatine kinase increase in all nine infants has been shown to be due to the muscle isoenzyme.

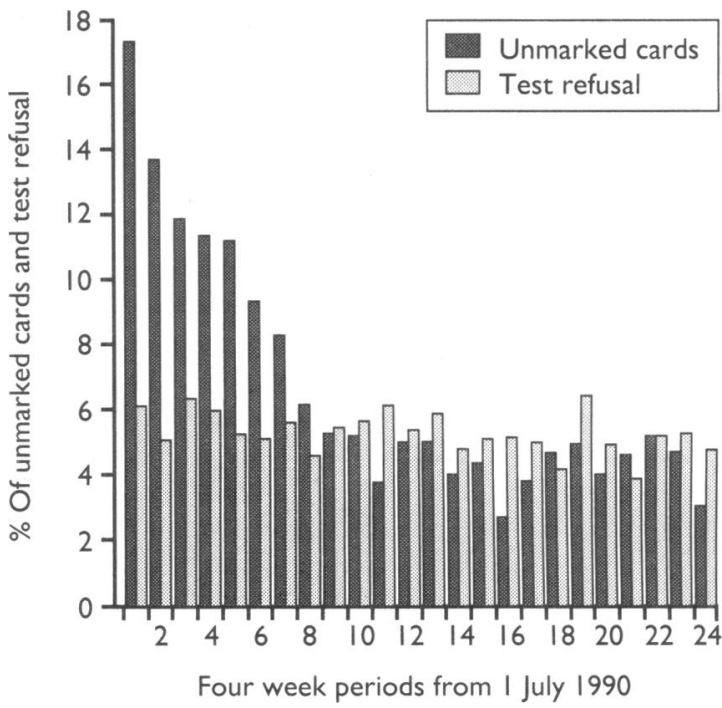

FIG 1-Decline in number of unmarked cards and test refusals over total period of study. $\square$ Percentage of unmarked cards $\square$ Percentage of test refusals

There have been seven infants with a transient elevation in creatine kinase activity. This is a rate of $1: 4888$ $(0.02 \%)$, which we consider acceptable and is in line with the best of current programmes, where rates of up to $0 \cdot 2 \%$ have been observed. ${ }^{612}$

\section{UPTAKE}

Since the programme started there has been a steady refusal rate of $5-6 \%$ (fig 1 ). One problem which proved far greater than anticipated was where no option was marked on the screening card. This was in excess of $10 \%$ for the first few months and was over $20 \%$ in some parts of Wales. As testing was done on the basis of parental choice these infants would not be screened. Parents may have opted for the test, however, and, hearing nothing more, might assume that the result was normal. If they were subsequently found to have an affected son, the apparent failure of the programme would bring it into unjustified disrepute. We were anxious therefore to reduce to a minimum the number of samples where parental choice was unclear so from November 1990 we sent lists of infants untested to the local health district at the end of each month so that parental choice could be checked while the original sample was still usable. This approach led to a steady decline in the number with no stated option (fig 1) and produced a steady stream of information about infants on the lists: requests to test, occasional refusals, and corrections of erroneous sex assignment on the sample. The response to these lists, however, has been also quite variable (fig 2), ranging from some districts supplying information on over $80 \%$ of the infants listed to one with an $8 \%$ response. Nevertheless, this 


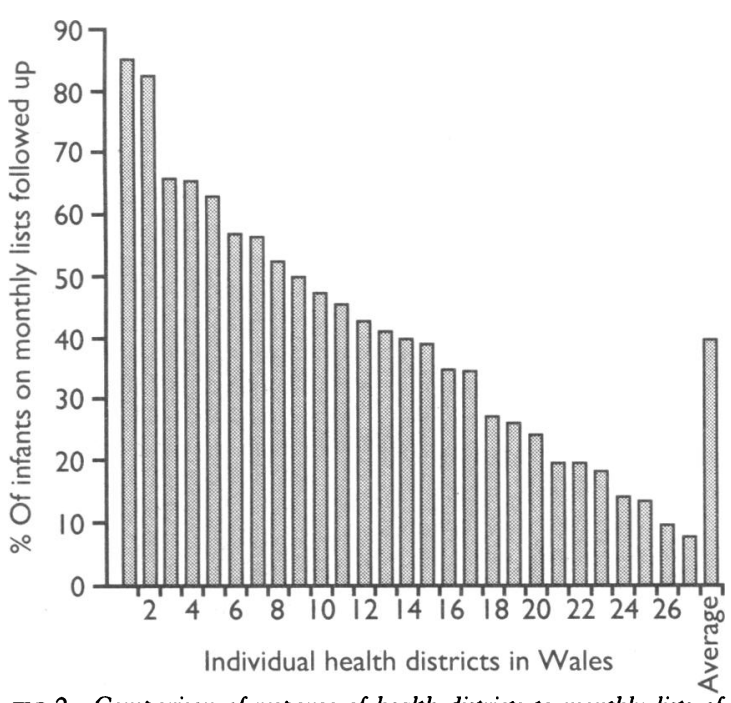

FIG 2-Comparison of response of health districts to monthly lists of infants not tested because parental choice was not clear

approach has reduced the percentage of samples with no parental choice recorded to $3 \%$.

\section{TRANSIENT CASES}

Though our screening method is semiquantitative, the seven unconfirmed cases did have creatine kinase values lower than those which were subsequently confirmed as increased on a later venous sample. Interestingly, five of these infants had some unusual perinatal features. One had been given intramuscular ampicillin for a septic cord; one had had a traumatic caesarean birth; one had had a difficult birth with vacuum extraction and he also had a ventricular septal defect; one had a heart murmur; and one had been premature and in a special care unit with hypotonia and jaundice. There is no evidence from any of the screening programmes to suggest that a transient elevation of creatine kinase activity in a neonate may lead to developing a muscular dystrophy in later life.

All seven families with a transient result were interviewed to gain their perspective of the programme and ensure they had no lingering doubts about their sons' health. Generally anxiety was minimal with two exceptions. One experienced considerable anxiety waiting for the result of the venous creatine kinase test because there was a family history of Duchenne muscular dystrophy on the maternal father's side. The other family were made aware of the need for the venous sample some 24 hours before it was taken and were then not given the normal result for a further 24 hours. Nevertheless, all the families were positive about the programme and would have another infant tested.

False positive results with a persistently elevated creatine kinase activity have been reported for the dominantly inherited but benign blood anomaly in which the creatine kinase BB isoenzyme is elevated in erythrocytes and thrombocytes. ${ }^{13}$ They might also occur in infants with congenital hypothyroidism ${ }^{14}$ and in a few other muscle disorders; for example, the Manitoba group reported a false positive in an infant with a congenital myopathy as part of the WalkerWarburg syndrome. ${ }^{15}$ It is too early to know of any false negatives but these would probably arise only by laboratory or administrative error.

\section{POSITIVE CASES}

Gene studies-All nine families in which the babies had persistent creatine kinase elevation chose to have DNA analysis. Five of the nine infants have been shown to be deleted from part of the Duchenne muscular dystrophy gene (table II). Our laboratory had been routinely screening with probes $\mathrm{cf} 56 \mathrm{a}$, cf56b, and $9-7$, which cover about $93 \%$ of deletions in our population. ${ }^{16}$ We have recently altered this practice and now use a multiplex polymerase chain reaction that detects $98 \%$ of mutations, and we use Southern blotting analysis for confirmation. This reduces reporting time to a few days.

Muscle biopsies-Though all nine families opted for DNA analysis only five then chose to follow up with muscle biopsy and dystrophin analysis. This confirmed Duchenne muscular dystrophy in each case (table II). In family 5 the mother's brother had previously been confirmed by muscle biopsy and so a biopsy on the infant was thought unnecessary. In spite of increasing knowledge about the gene, at the present time the only way to distinguish between Duchenne muscular dystrophy and the more benign allelic Becker muscular dystrophy is by muscle biopsy and dystrophin analysis. Though the incidence of Becker is only one tenth that of Duchenne muscular dystrophy, the three families who refused a biopsy did so on the grounds that while they accepted their son had a muscular dystrophy they preferred to live in the hope that it might be Becker and so chose not to complete the diagnostic process.

Familial cases-In two cases the screening programme identified two affected boys in a sibship before the elder boy had been diagnosed (table II). When family 1 was detected the elder brother was under orthopaedic management for his abnormal gait but Duchenne muscular dystrophy had not been suspected. Seven mothers seem to be carriers based on their serum creatine kinase values. The mother in family 5 had a brother with Duchenne muscular dystrophy.

Genetic counselling was sought by all nine families, but it is still too soon to comment on their reproductive choices. Prenatal diagnosis, however, has been performed on the fetus of the aunt of one boy, and genetic counselling has been requested by several other members of the extended families.

Experience of the families-It would be neither feasible nor desirable to intrude upon these families at frequent intervals to monitor their response to the emergent diagnosis of Duchenne muscular dystrophy. We have therefore sought only one in-depth interview with each family so far, about six months after the positive screening test; any other direct contact with the families has been limited and only when sought by them. To monitor their responses we have kept in close touch with each family's health visitor. The health visitors have maintained frequent contact, and we have guided their observations to record specific aspects of the evolving mother and baby relationship. This information has proved invaluable and could not have been gathered in any other way.

Emotional trauma-The detailed results of the social evaluation will be reported elsewhere, but so far only one of the nine families seems to have experienced an above average level of emotional trauma. The others have been very positive about the programme, stating that they preferred to know about their sons' condition from an early stage. Apparently this family was not given the information sheet about the programme, and they feel that, had they seen it, they would have refused the test. The disclosure about their son's positive test result was made at 2 to 3 weeks. Their health visitor noted a difference in mother's handling of the baby and visitors were no longer encouraged to hold the boy. This lasted for some weeks but at no time was the baby at risk either physically or psychologically nor was the mother and baby bond threatened. There were additional factors with this family which compounded their inevitable distress, not least the subsequent diagnosis of Duchenne muscular dystrophy in an elder son, in whom signs of clinical abnormality had been recognised before the birth of his younger brother. 
This family was the second detected and our practice has since been modified to make a disclosure no sooner than 6 weeks. Interestingly, this family lives in the area that is our poorest responder to the monthly listings of infants where parental choice was not stated on the screening sample (fig 2 , area 27 ). The refusal rate in this area is now the highest in Wales and increased dramatically after the disclosure (fig 3). Probably, in a close-knit community the negative response of this family has influenced the uptake of the test. Our concern is not the actual refusal rate but to ensure that families have choice on the basis of informed consent. As part of the study of the emotional response of families to the early diagnosis of Duchenne muscular dystrophy we are also interviewing those families whose boys have undergone the later traditional diagnosis. This will allow us to compare the experiences of both groups.

Implications for community education-From the outset, we have devoted a lot of effort to providing a continuing educational programme for health professionals. The importance of this cannot be overemphasised. The response from midwives, health visitors, and paediatricians to the education programme has generally been positive and has helped in the practical implementation of the test. It has also enabled the health professionals to give us feedback on the screening from their perspective.

\section{Conclusion}

When screening began we agreed to discontinue it at the. end of the first year if there were a number of traumatised families. This has not been the case; in fact most families have been pleased to know the diagnosis so early. This permits future informed reproductive planning, avoids diagnostic complications and delays, and allows planning of care for the affected boy. We are confident that the programme should continue to permit a full evaluation of the issues raised by screening newborn males for Duchenne muscular dystrophy and hope to extend its duration so that the perspectives of the families may be assessed as the boys develop symptoms and signs of muscular weakness.

We also believe that this project will serve as a model for the evaluation of other community genetic interventions, with its emphasis on offering optional tests based on informed consent and the education of primary health care teams.

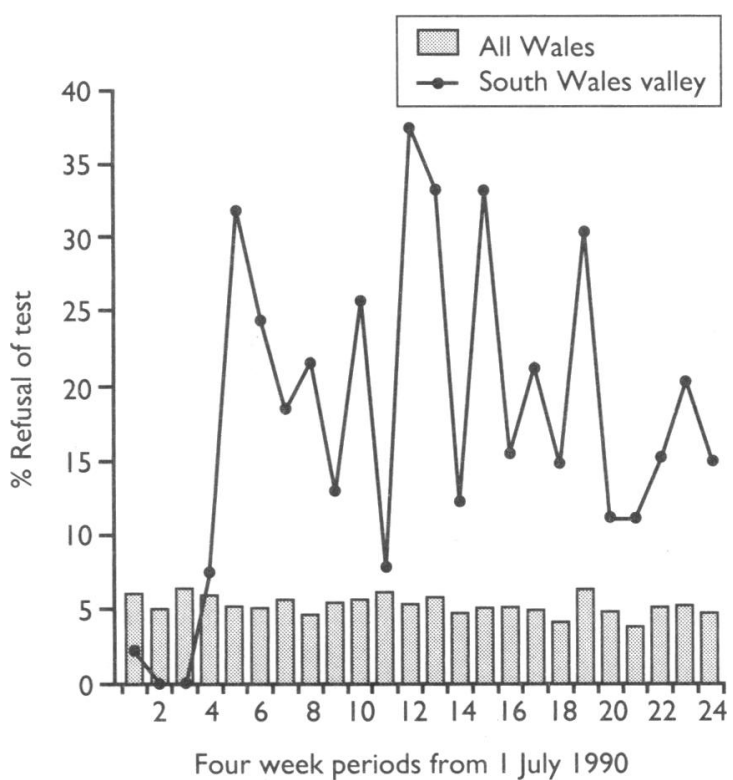

FIG 3-Comparison of refusal rate for test in one South Wales valley with all Wales average. Wales valley refusal rate
This work is being supported by a grant from the Muscular Dystrophy Group of Great Britain. We would like to thank all the families for their willingness to be included in this study. We wish to thank J Hawkins and D Rees for creatine kinase analyses; L Lazarou and L Rosser for mutation analyses; L Nicholson (Newcastle General Hospital) and C WallgrenPettersen for dystrophin analyses; J Fenton-May for clinical assistance; J Davies and L Mahoney for clerical assistance; and Peter Harper for continued encouragement. This study has been helped considerably by the cooperation of the nominated paediatricians: Drs $N$ K Agarwal (Singleton Hospital), P D L Edwards (Princess of Wales Hospital), R W Evans (Prince Charles Hospital), A Goodwin (West Wales General Hospital), A D Griffiths (Nevill Hall Hospital), B Griffiths (Neath General Hospital), D M Lewis (Bronglais General Hospital), S Maguire (Royal Gwent Hospital), J Morgan (East Glamorgan General Hospital), A Palit (Withybush Hospital), J R Sibert (Llandough Hospital), C B Vulliamy (Breconshire War Memorial Hospital), C M Weaver (University Hospital), $\mathrm{H}$ Williams (Wrexham Maelor Hospital), V L Woolley (Ysbyty Gwynedd), and T D Yuille (Glan Clwyd Hospital). The health visitors involved have also contributed greatly; without their efforts we could not have monitored the families so thoroughly: R Bird (Clwyd), A Davies (Mid Glamorgan), B Griffiths (Clwyd), M Home (Clwyd), G Jenkins (Mid Glamorgan), S Lloyd (Mid Glamorgan), M McLaughlin (Clwyd), A Milton (Mid Glamorgan), G Parker (South Glamorgan), M Pearce (Mid Glamorgan), D Rafferty (Powys), V Rees (East Dyfed), M Roberts (Gwynedd), M de Schoolmester (West Glamorgan), S Stevens (Pembrokeshire), J Thomas (Gwent), J Vaughan (Mid Glamorgan), K West (Pembrokeshire), A Williams (Clwyd), and $\mathrm{O}$ Williams (Mid Glamorgan). We are also grateful to the family practitioners involved for their cooperation.

Finally we wish to thank neurologists Drs S J Wallace (University Hospital) and R Appleton (Alder Hey Children's Hospital) for their diagnostic evaluations and paediatricians and Drs B M Ansari (East Glamorgan General Hospital), D W Fielding (Countess of Chester Hospital), and E R VerrierJones (Llandough Hospital) who have each been involved with a positive screening case.

1 Zellweger H, Antonik A. Newborn screening for Duchenne muscula dystrophy. Pediatrics 1975;55:30-4.

2 Scheuerbrandt G, Mortier W. Voluntary newborn screening for Duchenn muscular dystrophy, a nationwide pilot program in West Germany. In Naruse H, Irie M, eds. Neonatal screening. Amsterdam: Excerpta Medica, 1983:352-7.

3 Planchu H, Dorche C, Carrier NH, Cordier MP, Guibaud P, Lauras B, et al. Systematic neonatal screening for Duchenne muscular dystrophy: results of a ten year study in Lyon, France. In: Therell BL, ed. Advances in neonatal a ten year study in Lyon, France. In: Therell

4 Drummond LM, Veale AMO. Muscular dystrophy screening. Lancet 1978;i: 1258-9.

5 Skinner RA, Emery AEH, Scheuerbrandt G, Syme J. Feasibility of neonata screening for Duchenne muscular dystrophy. F Med Gen 1982;19:1-3.

6 Jacobs HK, Wrogemann K, Greenberg CR, Seshia SS, Cameron AI. Neonata screening for Duchenne muscular dystrophy - the Canadian experience. In Schmidt BJ, et al, eds. Current trends in infant screening. Amsterdam: Elsevier, 1989:361-6.

7 Koenig M, Hoffman EP, Bertelson CJ, Monaco AP, Feener C, Kunkel LM Complete cloning of the Duchenne muscular dystrophy (DMD) cDNA an preliminary organization of the DMD gene in normal and affected individuals. Cell 1987;50:509-17.

8 Gardner-Medwin D, Bundey S, Green S. Early diagnosis of Duchenne muscular dystrophy. Lancet 1978;i:1102.

9 Smith RA, Rogers M, Bradley DM, Sibert JR, Harper PS Screening for Duchenne muscular dystrophy. Arch Dis Child 1989;64:1017-21.

10 Smith RA, Williams DK, Sibert JR, Harper PS. Attitudes of mothers to neonatal screening for Duchenne muscular dystrophy. BMF 1990;300: 1112.

11 Scheuerbrandt G. Voluntary infant screening for Duchenne muscular dystrophy in West Germany. In: Therell BL, ed. Advances in neonatal screening. Amsterdam: Elsevier, 1987:361-4.

12 Plauchu H, Dorche C, Cordier MP, Guibaud P, Robert JM. Duchenne muscular dystrophy: neonatal screening and prenatal diagnosis. Lance 1989;i:669.

13 Scheuerbrandt G, Lundin A, Lovgren T, Mortier W. Screening for Duchenne muscular dystrophy: an improved screening test for creatine kinase and its application in an infant screening programme. Muscle Nerve 1986;9:11-23.

14 Williams H, Hughes I, Harper PS, Bradley D. False positive creatine kinase test in hypothyroid male at risk for Duchenne muscular dystrophy. Lance 1984;ii:645-6.

15 Greenberg CR, Jacobs HK, Nylen TE, Gibb M, Chodirker BN, Moffatt M, et al. Congenital hydrocephalus secondary to Walker-Warburg syndrome et al. Congenital hydrocephalus secondary to Walker-Warburg syndrome identified on the Manitoba neonatal screening
muscular dystrophy. I Med Genet 1992;29:583-5.

16 Upadhyaya M, Smith RA, Thomas NST, Norman AM, Harper PS. Intragenic deletions in 164 boys with Duchenne muscular dystrophy (DMD) studied with dystrophin cDNA. Clin Gen 1990;37:456-62.

(Accepted 10 November 1992) 